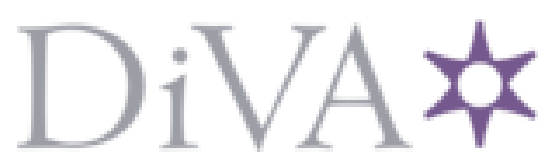

http://www.diva-portal.org

\title{
Postprint
}

This is the accepted version of a paper published in International Journal of Organizational Analysis. This paper has been peer-reviewed but does not include the final publisher proof-corrections or journal pagination.

Citation for the original published paper (version of record):

Andersén, J., Andersén, A. (2014)

Deconstructing resistance to organizational change - A social representation theory approach.

International Journal of Organizational Analysis, 22(3): 342-355

Access to the published version may require subscription.

N.B. When citing this work, cite the original published paper.

Permanent link to this version:

http://urn.kb.se/resolve?urn=urn:nbn:se:his:diva-9686 


\section{Deconstructing resistance to organizational change - a social representation theory approach}

\section{Introduction}

Dealing with resistance is a key feature of organizational change management. Resistance to change is a complex issue, however. Resistance to change and acceptance of change can be both rational and irrational (Wegener et al., 2004). In order to understand this complexity, several studies (e.g. Magala, 2009, Smircich and Morgan, 1982) have highlighted the importance of the notion that instead of managing change, we have to manage meaning. Consequently, in order to understand why some actors resist change whereas others accept it, we must understand how actors create meaning. Also, several authors have argued that the creation of meaning in the context of resistance to or acceptance of change have to be understood from a social psychological standpoint (Ford et al., 2002, Macrì et al., 2002, Piderit, 2000). Thus, it is important to take the individual elements and the social context into consideration as well as the interplay between (individual) cognition and the social setting. In spite of this, most research on resistance to change has neglected an important stream of research in social psychology - the theory of social representations (SRT). This theory was developed by Serge Moscovici in his study of psychoanalysis in 1961 (Moscovici, 2008). Since then, SRT has received a great deal of attention in various research disciplines and it has become an important field in social psychology research in several (mainly non-English-speaking) countries. According to Wagner et al. (1999, p. 96) “a social representation is the ensemble of thoughts and feelings being expressed in verbal and overt behavior of actors which constitutes an object for a social group". Thus, SRT has a constructionist approach in the sense that the subject and the object are not regarded as being independent constructs (Abric, 2001, Moscovici, 1988). 
Although some studies in organizational theory have applied SRT frameworks (e.g. Kemp et al., 2010) and other studies have used SRT in order to analyze other types of resistance, for example resistance to the implementation of new information systems (Gal and Berente, 2008), no studies have used SRT at a more general level to explain resistance to organizational change. Although SRT has several similarities with other theories aiming to understand and explain how individuals and/or groups create meaning, SRT has some unique characteristics that make it a highly useful theory for understanding attitudes to organizational change. Sense-making, for example, generally focuses on the process of making sense of, often, abstract concepts or the communication process per se (Weick et al., 2005). SRT, however, deals with representations of usually well-defined objects and how these objects are represented by individuals in a social context in a complex and dynamic interplay. These objects do not necessarily have to be complex or abstract (at least not from a positivistic point of view) and social representations of, for example, specific diseases (Foster, 2001, Goodwin et al., 2003) and food (Huotilainen et al., 2006) have been examined in SRT studies. SRT also differs from representations in psychological research in the sense that the representations are imagined across minds instead of within minds (Wagner et al., 1999). According to Billig (1988, p. 2), SRT also differs from many other social psychology approaches “...in the sense that the emphasis will be shifted from laboratory studies, which seek to isolate variables in the abstract, towards being a social science, which examines socially shared beliefs, or social representations, in their actual social context". The theory also allows an analysis of micro-level issues regarding the representations of different objects (Dulipovici, 2009). Thus, SRT can help us to untangle the complexity of resistance by deconstructing the elements of resistance, thereby enabling us to pinpoint key factors that can influence the choice of whether or not to resist change.

The purpose of this paper is to illustrate how SRT can be used to understand the concept of resistance to organizational change. We will achieve this by reviewing and integrating literature on resistance to 
organizational change and SRT, and by deconstructing the construct of resistance from a social representation standpoint. The remainder of this paper is organized as follows. Firstly, we describe SRT and define some key concepts. Thereafter, SRT and resistance to organizational change are discussed in three sections based on some key SRT concepts: object, alter, and ego. Finally, we consider and discuss the conclusions of the paper.

\section{Social representation theory - definition and key concepts}

Moscovici (1963, p. 251) stated that a "social representation is defined as the elaborating of a social object by the community for the purpose of behaving and communicating". This is a common definition of a social representation, and in several SRT contributions - particularly the early ones - the social context was broadly defined by, for example, society, the community, or the public. However, in more contemporary contributions on SRT, the social context often constitutes smaller social entities, for example folk high school participants (Andersén, 2010), groups within an organization (Gal and Berente, 2008), or ethnic groups (Philogéne, 2001). When analyzing resistance to organizational change it is, of course, necessary to delimit the social entity to social groups within the organization. Thus, although a social representation can be defined in different ways (Howarth, 2006), the previously described definition of a social representation seems appropriate when analyzing social representations in an organizational setting, i.e. "a social representation is the ensemble of thoughts and feelings being expressed in verbal and overt behavior of actors which constitutes an object for a social group" (Wagner et al., 1999, p. 96). The interplay between the object (that is represented), the ego (the subject that is doing the representing), and the alter (the social context of the representation) constitutes basis of SRT and these three elements generate the social representation (Wagner et al., 1999). A social representation is therefore often illustrated as a triangle labeled as the ego-alter-object (representation) triad (Markova, 2000). 
An important feature of SRT that differentiates it from (especially) the American and the British view of social psychology is the integrated approach to the three key concepts (i.e. object, ego, and alter). Thus, objects are regarded as being socially constructed (Voelklein and Howarth, 2005). Markova (2000, p. 435) refers to this as a dialogical co-constructionist approach, in contrast to the "fundamentalist EgoObject dyad". Thus, the concept of social representations also differs from Durkheim's distinction between individual and collective representations in the sense that from an SRT standpoint it is impossible to construct (or represent) an object without taking both the alter and the ego into consideration (Moscovici, 1988). Consequently, according to SRT, "meaning is not an individual or private affair, but always implies the 'other', concrete or imagined. While individually cognized, in form, function and content, the presence of the 'other' is always implicated based on past social experience" (Bauer and Gaskell, 1999, p. 170). Also, social representations are not static and the object is socially constructed through ongoing communication with others (Lahlou, 2001).

In order to understand how social objects are developed, two concepts are frequently used: anchoring and objectification. These concepts are used to understand how new social representations are developed. When faced with a new object, the first step is a process of anchoring whereby the new object is contextualized and understood based on previous representations (Moscovici, 1984, Wagner et al., 1999). Thus, "all representations arise from our need to turn the strange into something familiar" (Moscovici, 1988, p. 234). Objectification is the process of generating the actual social representation of the object where the object becomes (more) tangible and less unknown (Bauer and Gaskell, 1999). Gal and Berente (2008) use the terror attacks on September 11, 2001 to illustrate these concepts. During the anchoring process, the attacks were discussed and understood in the context of previous terror attacks. Later, however, they were objectified into an object in their own right by being labeled "9/11". 
As with all objects, the social representations of this object can, however, differ significantly between different social groups. Thus, anchoring is more about stability in the sense that we use our existing representations to understand and make sense of new phenomena, whereas objectification is oriented towards change and the introduction of new concepts (Markova, 2000).

We will now turn our attention to how SRT can be used to understand and deconstruct resistance to organizational change. We will discuss this issue based on three key concepts in SRT: the object, the alter, and the ego(s).

\section{The object}

The first question we have to answer in order to develop an SRT-based framework for understanding resistance to change is to identify the object or the objects that govern the attitude to change. It is, of course, possible to regard the somewhat abstract concept of change as the object, and much research on resistance to organizational change has focused on the perceived outcome of the change. See, for example, the seminal contributions by Piderit (2000) and Ford et al. (2008); although both contributions criticize the contemporary discourse on research on resistance, they do not discuss sense-making of factors other than the perceived outcome of the change (at least not to any great extent). Other studies have concentrated on how groups and/or individuals create meaning of the change process (e.g. Gioia and Chittipeddi, 1991). However, according to SRT, representations of the objects are the core of the theory and these are used "...for the purpose of behaving and communicating" (Moscovici, 1963, p. 251). Thus, when using an SRT approach, it makes sense to deconstruct the concept of resistance in order to identify the social objects that can be regarded as antecedents to resistance. This will allow an analysis of specific objects and the interrelationships between the objects that are most likely to affect the attitude to change. Consequently, we have identified three main objects that are most likely to have 
an influence on whether or not resistance will occur: the pre-change situation, the change process, and the perceived post-change situation. These three objects govern the attitude to organizational change and are highly interrelated, as illustrated in figure 1.

\section{Insert Figure 1 here}

The social representation of the current situation, which we refer to as the pre-change situation, is of course highly relevant. First and foremost, the perception or representation of the pre-change situation will have a strong influence on the attitude to change. As pointed out in several studies (e.g. Armenakis et al., 1993, Kotter and Schlesinger, 1979, Spector, 1989), if the members of an organization are satisfied with the current situation, they are obviously more likely to reject proposals for change. Also, irrespective of whether or not these members are highly satisfied with the current conditions, it can be emotionally difficult to abandon old routines and practices (Wolfram Cox, 1997). However, from an SRT standpoint, the representation of the pre-change conditions has additional implications. The perceived post-change situation is a new condition and one that, in most cases, has not been represented previously. This novel situation is likely to be understood and anchored based on the representation of the current situation. Thus, the representation of the post-change situation will not only be related and compared to the pre-change situation, but the post-change situation will, at least initially, be anchored in the social representation of the pre-change situation. For example, let us assume that an organization is to change the quality management system by implementing a total quality management (TQM) philosophy (Hackman and Wageman, 1995, Powell, 1995). The perceived post-change situation of the implemented philosophy will not only be compared and related to the current quality management practices. Instead, due to the constructionist nature of SRT, the entire representation of the perceived implemented TQM system (i.e. the object) will be based on the current practices. Thus, how the new 
object is represented and perceived is highly influenced by and anchored in the existing representations (Markova, 2000, Moscovici, 1984, Wagner et al., 1999).

In addition to the two objects post-change situation and pre-change situation, the change process itself will influence whether or not resistance will occur. Much contemporary research on organizational change has highlighted that change rather than stability is natural for many organizations (Tsoukas and Chia, 2002) by, for example, using concepts such as "continuous change" (Brown and Eisenhardt, 1997) or by arguing for the use of the concept "organizing" instead of "organization" (Whittington, 2003). However, continuous change, especially what Weick and Quinn (1999) refers to as episodic change, can be a problem for organizations - and most organizations are unable to implement significant new changes on a continuous basis (Rumelt, 1995). For example, in resource-based theory, several authors have argued about the importance of stability and longevity for the development of sustainable competitive advantages (Andersén, 2011, Barney, 1991) and evolutionary theory has illustrated the importance of stability and incremental changes (Nelson and Winter, 1982). Thus, the process of change can be complex and it often demands time and effort from the members of an organization, which is not always appreciated. Consequently, if an organization has undergone several episodic changes, resistance is likely to occur despite the fact that there are positive representations of the post-change situation and negative representations of the pre-change situation.

To summarize our discussion concerning the objects, we can conclude that the three objects identified are highly interrelated. The representation of the post-change situation is highly influenced by the prechange situation due to the process of anchoring. Also, the representation of process of change itself is likely to be a source of resistance. The relevant question now is how these objects are socially represented; thus, we have to examine the social contexts within an organization. 


\section{The alter}

The "alter", i.e. the social entity that co-constructs the representation with the individual is, of course, crucial in order to understand how representations comes about. The social setting can be defined in different ways: for example, the nation, the community, the other person, or the group (Markova, 2000). When analyzing organizational change, it makes most sense to define the social entity as groups of individuals within the organization. It is important to be aware of the fact that individuals generally have several social representations of the same object (Bauer and Gaskell, 1999). This will be discussed at greater length in the next section. However, this also has relevance for defining the social entity because we must probably identify several social groups in order to understand resistance to change. Based on the study conducted by Bauer and Gaskell (1999), Gal and Berente (2008) argue that social groups can be identified by their functional role; for example, units or departments within the organization. However, it is more important to analyze natural groups, i.e. groups "characterized by a common socio-historical project that brings group members together through shared experiences, activities, and interests" (Gal and Berente, 2008, p. 146). Thus, formal groups can often be synonymous with informal groups and can, at least, give a hint of where to begin the identification of social entities. However, it is the natural groups that have to be the object of analysis when examining the alter aspect of the ego-alter-object triad (Markova, 2000).

As discussed in the object section of the article, when facing organizational change, members of an organization will create meaning of the post-change situation by mainly anchoring the perceived postchange situation in the social representations of the current situation (for example, if a firm intends to implement a TQM system, the perceptions of existing quality management practices are likely to influence the attitude to TQM). However, social representations are dynamic; new communication about the proposed change will occur and this will, of course, influence the different representations (i.e. mainly the representation of the pre-change and post-change situations and the change process as previously discussed) and therefore the attitude to the proposed change. By using the lens of SRT, we 
have a useful tool that can help us to understand and contextualize much previous research on resistance to change from a solid social psychology point of view. For example, Ford et al. (2002) suggest a more constructionist approach for understanding of resistance to change by analyzing the background conversations in organizations. Cynical and resigned background conversations are, for example, likely to generate a climate of resistance within an organization. However, the concept of background conversations is used at an overall organizational level (and not on different groups within the organization). It also tends to neglect the relationship between this conversation and individual cognition, and SRT can be used to untangle these issues.

In order to understand resistance from a managerial point of view, it makes sense to discuss how the social entity (the alter) can be affected. Several studies on organizational change have argued for the involvement of agents of change in the change process (e.g. Balogun, 2006, Dutton et al., 2001). Thus, in order to facilitate the process of change, managers and other advocates of change are recommended to communicate and interact with recipients of change and to be present in the daily work (Balogun, 2006). Using SRT terminology, in communicating with recipients of change, agents of change (i.e. those who advocates change) will be part of a social entity and co-construct social representations with other actors within the organization. Whereas most other studies have argued for the importance of having agents of change interacting with recipients of change in order to facilitate change processes, this notion has even more implications when using an SRT approach. When adopting a constructionist approach, the alter cannot be regarded as an isolated entity that is not influenced by other actors. Thus, when advocates of change are interacting in social contexts, their representation of the objects (mainly the pre-change and post-change situations and the change process) will be co-constructed with other actors. This viewpoint differs from the sense-making approach exemplified by this quotation from Balogun $(2006$, p. 47) on how to make senior managers more involved in order for them to give sense in change processes : "To achieve this, change leaders need to be present - either personally or through other change ambassadors - with the change recipients, as orchestrators and facilitators of change". 
Thus, in contrast to SRT, advocates of change will be regarded here as being sense-givers (Gioia and Chittipeddi, 1991) that will not themselves be influenced when interacting with other actors. According to SRT, the object(s) will be co-represented together when change agents and change recipients interact, and in this situation all parties can learn from each other and construct joint social representations. This notion supports the viewpoint expressed by, for example, Ford et al. (2008) and Piderit (2000) of a more balanced approach to change in which resistance does not have to be regarded as dysfunctional, or change agents as carriers of the ultimate truth. Thus, from an SRT standpoint and using sense-making terminology, all actors in the social entity will make sense and give sense together in the construction of social representations.

An important aspect concerning the social entity and the construction of social representations is that social representations have an element of stability (Howarth, 2006). Thus, representations are not always easily altered or replaced, and if change agents only interact with change recipients when changes are to be implemented, the potential for successful change is most likely not very good. It is therefore important for advocates of change to participate and communicate on a regular basis if they are to be regarded as part of a social group. This is most likely a crucial feature for effective management of meaning if organizations are to achieve what Armenakis et al. (1993) refer to as a readiness for organizational change.

\section{The ego(s)}

So far, we have described how the "object" and the "alter" of the ego-alter-object triad can be used in order to understand the concept of resistance to organizational change. We will now turn our attention to how the "ego" can be understood. The individual has two functions for social representations. Firstly, 
individuals do, of course, construct the representations. This aspect of the ego has been discussed throughout the paper, i.e. the anchoring and objectification of objects in a social context. Secondly, an important feature of SRT is that an individual is a member of several social entities and can therefore have several social representations of the same object. Different contextual factors will govern which representation(s) is/are present in a specific situation. In figure 2, we integrate the ego with the other aspects of SRT discussed so far.

\section{Insert Figure 2 here}

Figure 2 provides an overview of how SRT can be used to understand attitudes to organizational change. As illustrated in the figure, the basis for an understanding of resistance is the three social representations, i.e. the three three-dimensional triangles. Illustration of a social representation as a triangle, based on ego, alter, and object (Markova, 2000) or subject, subject and object (Jovchelovitch, 2002) is common in SRT research. Bauer and Gaskell (1999) developed the so-called "toblerone model" by making the triangle three-dimensional, where time is represented by the third dimension. In our proposed model, however, we use the third dimension to illustrate that an individual can have several representations of the same object. Thus, this dimension should be regarded from the point of view of the ego. Individuals will interact in various social contexts and several different representations of the same object will therefore occur. According to Howarth (2006), representations are both dialogic and polyphasic. In SRT, the presence of several sometimes contradictory representations is usually referred to as "cognitive polyphasia".

The concept of cognitive polyphasia has received much interest in SRT research. SRT rejects "the notion that cognitive systems habitually develop towards equilibrium, that is towards a state of consistency" 
and that "judgments are based on representational terms being dominant in one field of personal or group interests while playing a subordinate role in other fields" (Wagner et al., 2000, p. 304). Thus, the knowledge or belief about a certain object is not a linear process that transforms from one representation to another; instead, different forms of knowledge co-exist (Jovchelovitch, 2002). In order to understand these viewpoints, it is important to clarify the distinction between Durkheim's concepts "collective and individual representations" and "social representations". Durkheim's collective representations are synonymous with the "reality" and the "actual" conditions and individual representations are the interpretation of this reality. SRT, on the other hand, is a constructionist approach and individuals can have different "realities" depending on the social context (Foster, 2003, Howarth, 2006). Thus, we create the (socially constructed) reality in our interactions; the interactions will eventually result in social representations and these representations will govern our behavior, attitudes, and actions (Moscovici, 2008). We can use the concept of "organization" to illustrate cognitive polyphasia in action. The distinction between the formal and informal organization (Argyris, 1977) is common in organizational theory. These representations co-exist among most members of an organization and - as for all representations - the representations will govern behaviors and conducts. The representations of the various organizational elements can be conflicting: for example, regarding formal and informal leaders, formal and informal communication channels, and so on. Which representation will be present at any given time depends on different contextual factors.

Regarding the representation of the pre-change situation, these social representations are most likely quite established and will be the representations to which the new ideas (i.e. the change process and the post-change situation) are anchored. However, when individuals begin the sense-making process regarding the new objects, they will co-construct and objectify the new concepts, based on existing representations (anchoring) and on communication concerning the new objects. This is a dynamic 
process and, in the course of time - when new concepts are objectified - existing representations (for example, regarding the pre-change situation) can be re-represented and altered. Consequently, new representations will emerge and previous representations will be altered. However, many SRT scholars (e.g. Howarth, 2006, Wagner et al., 2000) argue that social representations are rarely completely abandoned. Instead, social representations can be present to a greater or lesser degree. For example, the attitude to the change will be discussed in various social contexts, within as well as outside the organization. In the context of the social entity of the family, the interaction will, of course, differ from the interaction in the natural social groups with other members of the organization; interaction with agents of change will differ from interaction with those who are skeptical of change, etc. Thus, the social representations that are present in a given situation can differ substantially between different social entities.

Let us return to the example in which an organization intends to implement TQM-philosophy by focusing on the social representations of a middle manager (ego). Let us assume that most employees (alter) are reluctant to implement TQM. In order for top management (alter) to secure acceptance for the change, it is important to communicate the benefits of the change to the employees. This is usually done by middle managers who, in this case, can be regarded as advocates of change. During the implementation process the middle manager interacts in two parallel social settings: communication with subordinates and communication with top management. Initially, the middle manager is informed about the benefits of TQM by top management and is, in our example, positive to the change. However, over time the middle manager can re-construct her/his perception of the change due to increased communication with co-workers (resulting from the representation of the objects, i.e. the change process and the pre- and post-change conditions). Thus, when co-constructing perceptions of TQM, it is uncertain whether the middle manager will influence co-workers or vice versa. Let us assume that the middle manager is influenced by co-workers and becomes more negative toward TQM. As a result, during the change process, she/he is likely to have a positive attitude toward TQM when interacting with top management and a negative one when communicating with co-workers. This is an example of cognitive polyphasia and illustrates the usefulness and dynamics of an SRT approach when analyzing 
attitudes toward change. Although the behavioral school of thought (Simon, 1957; Cyert \& March, 1963) argues that organizations consist of individuals with various goals and attitudes that must be taken into consideration, SRT helps us to understand how these attitudes are co- and re-constructed. Thus SRT constitutes a conceptual framework that explains how representations are developed and changed at a collective as well as at an individual level. It also goes beyond the sense-making/sense-giving approach of sense-making theory by acknowledging that all actors within an organization are likely to influence each other and consequently co-construct their representations in various social settings.

This discussion has illustrated the complexity of resistance and how different social representations are likely to influence the attitude to organizational change, sometimes in different directions, due to cognitive polyphasia. Thus, in order to manage how individuals and groups co-construct meaning, we have to untangle and deconstruct the elements that will influence the attitude to change.

\section{Conclusions}

In this article, we have described how SRT can be used to understand resistance to organizational change. A key conclusion of our study is that if the social representations of the pre-change and postchange situations and the change process differ considerably between individuals and groups within the organization, resistance will be more likely to occur. This notion is neither new nor controversial and the object dimension of the proposed model (i.e. figure 1) has been identified and discussed in numerous studies. For example, concepts such as expectations and opinions of the current situation were thoroughly discussed by Simon (1957). However, in contrast to the behavioral school of thought or sense-making theory, SRT can provide a more dynamic conceptual framework for understanding how attitudes toward change can shift and co-exist, even at individual level, by taking various social settings and the co-construction element into consideration. To achieve less diversified social representations within an organization is a highly complex task, however. Due to the fact that individuals can have numerous different representations of the same object, one can imagine the complexity of dealing and

(c) Emerald Group Publishing Limited

This is a pre-print of a paper and is subject to change before publication. This pre-print is made available with the understanding that it will not be reproduced or stored in a retrieval system without the permission of Emerald Group Publishing Limited. 
managing social representations (i.e. meaning) at an organizational level. Thus, the micro-management of all the separate elements of our model (figure 2 ) is probably a virtually impossible task. The model can, however, provide an overview of how meaning and representation are constructed from an SRT standpoint and it can function as a useful deconstruction of resistance to change.

An important implication of the present study is that is has highlighted the importance of communication between different levels in an organization. This has been discussed in numerous previous studies (e.g. Balogun, 2006, Cyert \& March, 1963; Gioia and Chittipeddi, 1991, Weick et al., 2005). However, in contrast to many of these studies, we reject the viewpoint of agents of change as unbiased sense-givers and other actors as receptors of change that receive the wisdom and objectivity of the advocates of change, so that they can make sense of the change process. According to SRT, all actors are subjects who co-create representations and thereby meaning. This feature is unique to SRT and provides an overall framework, in which alter, ego, object, and context are taken into account. Thus, enhanced communication is likely to generate less diversified social representations in the organization. The end result of this will, however, not always result in organizational change, due to the fact that advocates of change will also be influenced by skeptics of change. Consequently, increased communication is likely to stimulate organizational harmony more than organizational change.

This article has only provided a brief overview of SRT and its implications for resistance to organizational change, and the various elements discussed can be elaborated more in future studies. For example, the interrelations between the three objects (pre-change and post-change situations and the change process), the identification of common paths for the processes of anchoring and objectification regarding organizational change, the effect that differentiated social representations as opposed to joint social representations within an organization have on resistance, and how different contextual factors govern which social representations (i.e. cognitive polyphasia) will be manifested are all interesting

(c) Emerald Group Publishing Limited

This is a pre-print of a paper and is subject to change before publication. This pre-print is made available with the understanding that it will not be reproduced or stored in a retrieval system without the permission of Emerald Group Publishing Limited. 
areas to be examined in future studies. SRT can provide a solid theoretical foundation and reliable

methodologies for deciding how best to examine such areas.

\section{References}

Abric, J.C. (2001), "A structural approach to social representations", In Representations of the social: Bridging theoretical traditions. Deaux, K. \& Philogéne, G. (Eds.), Blackwell Publishers Ltd., Oxford UK, pp. 42-47.

Andersén, A. (2010), "Social representations and social identity in Swedish folk high schools: an application of Duveen and Lloyd", Papers on Social Representations, Vol. 19, pp. 10.1-10.14.

Andersén, J. (2011), "Strategic resources and firm performance", Management Decision, Vol. 49, No. 1, pp. 87-98.

Argyris, C. (1977), "Organizational learning and management information systems", Accounting, Organizations and Society, Vol. 2, No. 2, pp. 113-123.

Armenakis, A.A., Harris, S.G. and Mossholder, K.W. (1993), "Creating readiness for organizational change", Human Relations, Vol. 46, No. 6, pp. 681-703.

Balogun, J. (2006), "Managing change: steering a course between intended strategies and unanticipated outcomes", Long Range Planning, Vol. 39, No. 1, pp. 29-49.

Barney, J.B. (1991), "Firm resources and sustained competitive advantage", Journal of Management, Vol. 17, No. 1, pp. 99-120.

Bauer, M.W. and Gaskell, G. (1999), "Towards a paradigm for research on social representations", Journal for the Theory of Social Behaviour, Vol. 29, No. 2, pp. 163-186.

Billig, M. (1988), "Social representation, objectification and anchoring: a rhetorical analysis", Social Behaviour, Vol. 3, No. 1, pp. 1-16.

Brown, S.L. and Eisenhardt, K.M. (1997), "The art of continuous change: linking complexity theory and time-paced evolution in relentlessly shifting organizations", Administrative Science Quarterly, Vol. 42, No. 1, pp. 1-34.

Cyert, R. and March, J. (1963) Behavioral theory of the firm. Blackwell Publishers, Oxford, UK.

Dulipovici, A.M. (2009), Exploring IT-based knowledge sharing practices: Representing knowledge within and across projects, Computer Information Systems Dissertations, Paper 33, available at: http://digitalarchive.gsu.edu/cis_diss/33 (accessed 28 September 2011).

Dutton, J.E., Ashford, S.J., O'Neill, R.M. and Lawrence, K.A. (2001), "Moves that matter: issue selling and organizational change", Academy of Management Journal, Vol. 44, No. 4, pp. 716-736.

Ford, J.D., Ford, L.W. and D'Amelio, A. (2008), "Resistance to change: the rest of the story", The Academy of Management Review, Vol. 33, No. 2, pp. 362-377.

Ford, J.D., Ford, L.W. and McNamara, R.T. (2002), "Resistance and the background conversations of change", Journal of Organizational Change Management, Vol. 15, No. 2, pp. 105-121.

Foster, J. (2001), "Unification and differentiation: a study of the social representations of mental illness", Papers on social Representations, Vol. 10, No. 3, pp. 1-18.

Foster, J.L.H. (2003), "Beyond otherness: controllability and location in mental health service client's representations of mental health problems", Journal of Health Psychology, Vol. 8, No. 5, pp. 632644. 
Gal, U. and Berente, N. (2008), "A social representations perspective on information systems implementation: rethinking the concept of "frames" ", Information Technology \& People, Vol. 21, No. 2, pp. 133-154.

Gioia, D.A. and Chittipeddi, K. (1991), "Sensemaking and sensegiving in strategic change initiation", Strategic Management Journal, Vol. 12, No. 6, pp. 433-448.

Goodwin, R., Kozlova, A., Kwiatkowska, A., Anh Nguyen Luu, L., Nizharadze, G., Realo, A., Külvet, A. and Rämmer, A. (2003), "Social representations of HIV/AIDS in Central and Eastern Europe", Social Science \& Medicine, Vol. 56, No. 7, pp. 1373-1384.

Hackman, J.R. and Wageman, R. (1995), "Total quality management: empirical, conceptual, and practical issues", Administrative Science Quarterly, Vol. 40, No. 2, pp. 309-342.

Howarth, C. (2006), "A social representation is not a quiet thing: exploring the critical potential of social representations theory", British Journal of Social Psychology, Vol. 45, No. 1, pp. 65-86.

Huotilainen, A., Pirttila-backman, A.M. and Tuorila, H. (2006), "How innovativeness relates to social representation of new foods and to the willingness to try and use such foods", Food Quality and Preference, Vol. 17, No. 5, pp. 353-361.

Jovchelovitch, S. (2002), "Re-thinking the diversity of knowledge: cognitive polyphasia, belief and representation", Psychologie et Société, Vol. 5, No. 1, pp. 121-138.

Kemp, D., Keenan, J. and Gronow, J. (2010), "Strategic resource or ideal source? discourse, organizational change and CSR", Journal of Organizational Change Management, Vol. 23, No. 5, pp. 578-594.

Kotter, J.P. and Schlesinger, L.A. (1979), "Choosing strategies for change", Harvard Business Review, Vol. 57, pp. 106-114.

Lahlou, S. (2001), "Functional aspects of social representation", In Representations of the social: Bridging theoretical traditions. Deaux, K. \& Philogéne, G. (Eds.), Blackwell Publishers Ltd., Oxford UK, pp. 131-146.

Macrì, D.M., Tagliaventi, M.R. and Bertolotti, F. (2002), "A grounded theory for resistance to change in a small organization", Journal of Organizational Change Management, Vol. 15, No. 3, pp. 292-310.

Magala, S. (2009), The Management of Meaning in Organizations, Palgrave Macmillan, New York, NY.

Markova, I. (2000), "Amédée or how to get rid of it: social representations from a dialogical perspective", Culture \& Psychology, Vol. 6, No. 4, pp. 419-460.

Moscovici, S. (1963), "Attitudes and opinions", Annual Review of Psychology, Vol. 14, No. 1, pp. 231-260.

Moscovici, S. (1984), "The phenomenon of social representations", In Social representations. Farr, R. \& Moscovici, S. (Eds.), Cambridge University Press, Cambridge, Mass., pp. 3-69.

Moscovici, S. (1988), "Notes towards a description of social representations", European journal of social psychology, Vol. 18, No. 3, pp. 211-250.

Moscovici, S. (2008), Psychoanalysis: Its image and its public, Polity Press, Cambridge, Mass.

Nelson, R.R. and Winter, S.G. (1982), An evolutionary theory of economic change, Harvard University Press, Cambridge, Mass.

Philogéne, G. (2001), "From race to culture: the emergence of African American", In Representations of the social: Bridging theoretical traditions. Deaux, K. \& Philogéne, G. (Eds.), Blackwell Publishers Ltd., Oxford UK, pp. 113-128.

Piderit, S.K. (2000), "Rethinking resistance and recognizing ambivalence: a multidimensional view of attitudes toward an organizational change", Academy of Management Review, Vol. 25, No. 4, pp. 783-794.

Powell, T.C. (1995), "Total quality management as competitive advantage: a review and empirical study", Strategic Management Journal, Vol. 16, No. 1, pp. 15-37. 
Rumelt, R.P. (1995), "Inertia and transformation", In Resource-based and Evolutionary Theories of the Firm-Towards a Synthesis. Montgomery, C. (Ed.) Kluwer Academic Publishers, Norwell, Mass., pp. 101-132.

Simon, H. (1957). Administrative behavior. MacMillan, New York, NY.

Smircich, L. and Morgan, G. (1982), "Leadership: the management of meaning", Journal of Applied Behavioral Science, Vol. 18, No. 3, pp. 257-273.

Spector, B. (1989), "From bogged down to fired up: inspiring organizational change", Sloan Management Review, Vol. 30, No. 4, pp. 32-46.

Tsoukas, H. and Chia, R. (2002), "On organizational becoming: rethinking organizational change", Organization Science, Vol. 13, No. 5, pp. 567-582.

Wagner, W., Duveen, G., Farr, R., Jovchelovitch, S., Lorenzi Cioldi, F., Markova, I. and Rose, D. (1999), "Theory and method of social representations", Asian Journal of Social Psychology, Vol. 2, No. 1, pp. 95-125.

Wagner, W., Duveen, G., Verma, J. and Themel, M. (2000), "II have some faith and at the same time I don't believe'-cognitive polyphasia and cultural change in India", Journal of Community \& Applied Social Psychology, Vol. 10, No. 4, pp. 301-314.

Wegener, D.T., Petty, R.E., Smoak, N.D. and Fabrigar, L.R. (2004), "Multiple routes to resisting attitude change", In Resistance and persuasion. Knowles, E.S. \& Linn, J.A. (Eds.), Lawrence Erlbaum Associates, Mahwah NJ, pp. 13-38.

Weick, K.E. and Quinn, R.E. (1999), "Organizational change and development", Annual Review of Psychology, Vol. 50, No. 1, pp. 361-386.

Weick, K.E., Sutcliffe, K.M. and Obstfeld, D. (2005), "Organizing and the process of sensemaking", Organization Science, Vol. 16, No. 4, pp. 409-421.

Whittington, R. (2003), "The work of strategizing and organizing: for a practice perspective", Strategic Organization, Vol. 1, No. 1, pp. 117-126.

Voelklein, C. and Howarth, C. (2005), "A review of controversies about social representations theory: A British debate", Culture \& Psychology, Vol. 11, No. 4, pp. 431.

Wolfram Cox, J.R. (1997), "Manufacturing the past: loss and absence in organizational change", Organization Studies, Vol. 18, No. 4, pp. 623-654. 


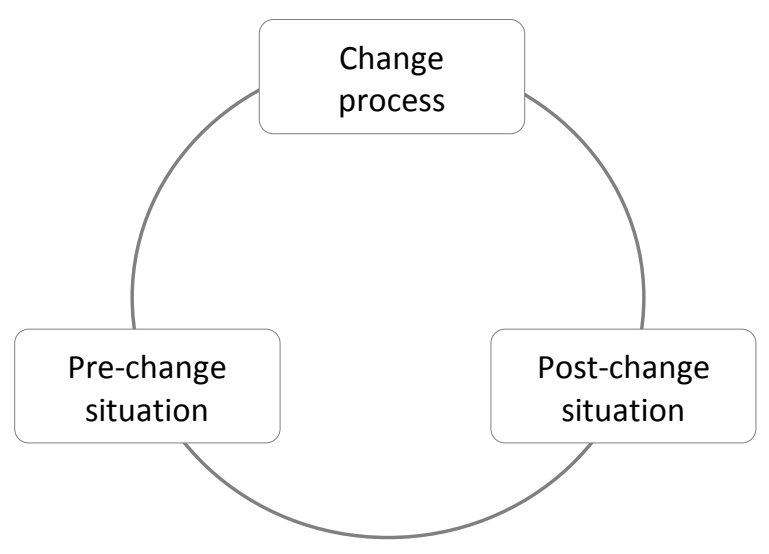

Figure 1. Objects that govern attitudes to change

(c) Emerald Group Publishing Limited

This is a pre-print of a paper and is subject to change before publication. This pre-print is made available with the understanding that it will not be reproduced or stored in a retrieval system without the permission of Emerald Group Publishing Limited. 


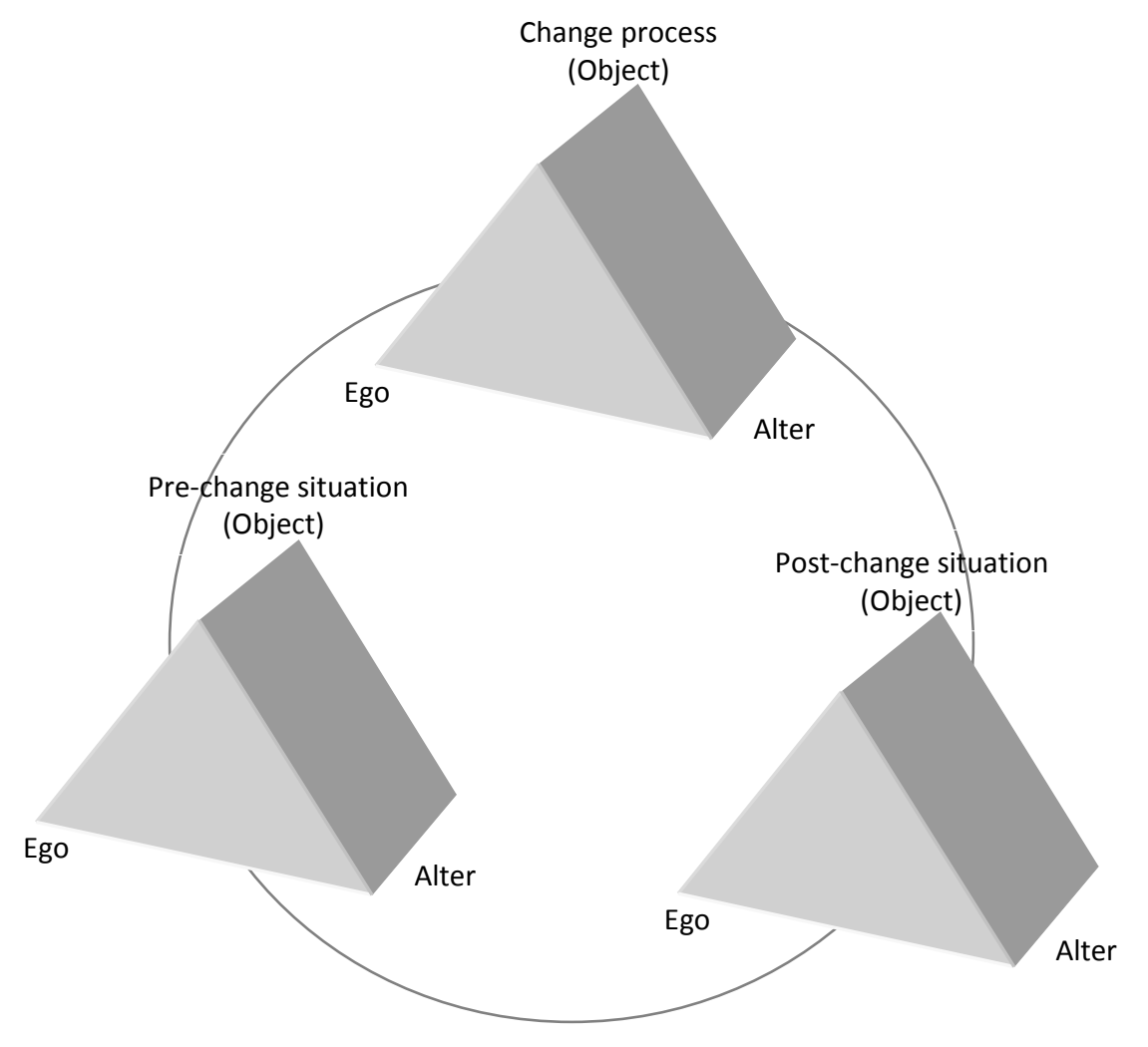

Figure 2. Organizational change from an SRT standpoint

(c) Emerald Group Publishing Limited

This is a pre-print of a paper and is subject to change before publication. This pre-print is made available with the understanding that it will not be reproduced or stored in a retrieval system without the permission of Emerald Group Publishing Limited. 